\title{
Guía de Práctica Clínica: Evaluación y manejo inicial de la enfermedad febril en el niño menor de cinco años
}

Initial assess and management of feverish illness in children younger than five years old (NICE clinical guideline 47, may 2007)

Traducido con autorización del National Institute for Health and Clinical Excellence (NICE). Disponible en: www.nice.org.uk/CG04

\section{Introducción}

Las enfermedades infecciosas son una causa muy importante de morbi-mortalidad infantil. La fiebre en los niños pequeños usualmente indica la presencia de infección, e identificar la causa puede representar un gran desafío diagnóstico. Como el manejo de la enfermedad febril es muy variable, el National Institute for Clinical Excellence (NICE) propone una guía de práctica clínica nacional como herramienta para mejorar su evaluación y manejo en todos los niños del Reino Unido.

La siguiente guía debería ser empleada en la evaluación y manejo iniciales de niños menores de cinco años con enfermedad febril hasta alcanzar el diagnóstico clínico de la enfermedad subyacente, usando para su tratamiento específico las guías locales o nacionales que correspondan a esa enfermedad.

\section{Detección de la fiebre}

En niños menores de cinco años de edad, los profesionales de la salud deberían medir la temperatura corporal a través de uno de los siguientes métodos: termómetro electrónico en axila, termómetro de punto químico en axila, o termómetro timpánico infrarrojo (los dos últimos a partir de las cuatro semanas de edad). Por el contrario, no debería medirse rutinariamente la temperatura por vía bucal o rectal, o mediante los termómetros químicos para medir sobre la frente.
La percepción paterna de fiebre debe ser considerada válida y tomada seriamente por los profesionales de la salud; mientras que la duración o intensidad de la fiebre no debe considerarse de manera aislada para predecir la probabilidad de enfermedad seria. Por otro lado, ante todo niño febril los profesionales de la salud deberían medir y registrar la temperatura, frecuencia cardiaca, frecuencia respiratoria y el tiempo de relleno capilar como parte de la evaluación de rutina de un niño con fiebre. La frecuencia cardiaca elevada puede ser un signo de enfermedad seria, en particular de shock séptico. Si existe evidencia de compromiso circulatorio (frecuencia cardiaca o tiempo de relleno capilar anormales), se deberá medir la tensión arterial del niño. Se debería considerar la posibilidad de una infección no endémica si el niño ha viajado recientemente a países extranjeros.

Evaluación y manejo de un niño con fiebre de acuerdo al riesgo de enfermedad seria

La evaluación clínica debería consistir en tres etapas: a) Identificar situaciones que amenazan la vida (vía aérea, ventilación, circulación, déficit neurológico), recurriendo en ese caso de manera inmediata a cuidados médicos de emergencia; b) Evaluar el riesgo de enfermedad seria utilizando el sistema de luces de semáforo (tabla 1); y c) Intentar identificar un foco de infección o la presencia de signos asociados a enfermedades específicas serias (tabla 2).

Tabla 1: Sistema de luces de semáforo para identificar el riesgo de enfermedad seria en niños con fiebre.

\begin{tabular}{|c|c|c|c|}
\hline & Verde - Bajo Riesgo & Amarillo - Riesgo Intermedio & Rojo - Alto Riesgo \\
\hline Color & - Color normal de la piel, labios y lengua & - Palidez observada por padre 0 cuidador & - Palidez/cianosis \\
\hline Actividad & $\begin{array}{l}\text { - Responde normalmente a estímulos sociales } \\
\text { - Contento/sonríe } \\
\text { - Se mantiene despierto o se despierta } \\
\text { rápidamente } \\
\text { - Llanto fuerte normal/sin llanto. }\end{array}$ & $\begin{array}{l}\text { - No responde normalmente a estímulos sociales } \\
\text { - Se despierta sólo con la estimulación prolongada } \\
\text { - Actividad disminuida } \\
\text { - No sonríe }\end{array}$ & $\begin{array}{l}\text { - No responde a estímulos sociales } \\
\text { - Impresiona enfermo al profesional de la salud } \\
\text { - Incapaz de despertarse o de mantenerse despierto } \\
\text { - Llanto débil, agudo o continuo }\end{array}$ \\
\hline Respiración & - Normal & $\begin{array}{l}\text { - Aleteo nasal } \\
\text { - Taquipnea: } \\
\text { FR }>50 \text { resp/min en } 6 \text { a } 12 \text { meses de edad } \\
\text { FR }>40 \text { resp/min en }>12 \text { meses de edad } \\
\text { - Saturación de oxígeno } \otimes 95 \% \text { respirando aire } \\
\text { ambiente } \\
\text { - Crepitantes }\end{array}$ & $\begin{array}{l}\text { - Gruñidos } \\
\text { - Taquipnea: FR >60 resp/min } \\
\text { - Tiraje moderado a severo }\end{array}$ \\
\hline Hidratación & $\begin{array}{l}\text { - Ojos y piel normales } \\
\text { - Membranas mucosas húmedas }\end{array}$ & $\begin{array}{l}\text { - Membranas mucosas secas } \\
\text { - Alimentación deficiente en lactantes } \\
\text { - Tiempo de relleno capilar } \geq 3 \text { segundos } \\
\text { - Reducción del ritmo diurético }\end{array}$ & - Reducción del turgor de la piel \\
\hline Otros & - Ninguno de los signos amarillos o rojos & $\begin{array}{l}\text { - Fiebre } \geq 5 \text { días } \\
\text { - Edema de un miembro o articulación } \\
\text { - No tolera el peso o no utiliza una extremidad } \\
\text { - Nuevo bulto }>2 \mathrm{~cm}\end{array}$ & $\begin{array}{l}\text { - } \mathrm{T} \geq 38^{\circ} \mathrm{C} \text { en niños de } 0 \text { a } 3 \text { meses } \\
\text { - } \mathrm{T} \geq 39^{\circ} \mathrm{C} \text { en niños de } 3 \text { a } 6 \text { meses } \\
\text { - Rash que no desparece a la vitropresión } \\
\text { - Fontanela tensa } \\
\text { - Rigidez de nuca } \\
\text { - Status convulsivo } \\
\text { - Signos neurológicos de foco } \\
\text { - Convulsiones focales } \\
\text { - Vómito bilioso }\end{array}$ \\
\hline
\end{tabular}

T: temperatura; FR: frecuencia respiratoria 
Tabla 2: Síntomas y signos de enfermedades específicas en niños con fiebre.

\begin{tabular}{|c|c|}
\hline Diagnóstico a considerar & Sintomas y signos en asociación con fiebre \\
\hline Enfermedad meningocóccica & $\begin{array}{l}\text { Rash que no desaparece a la vitropresión, particularmente acompañado de uno o más de los siguientes: } \\
\text { - Niño que luce enfermo. } \\
\text { - Lesiones }>2 \mathrm{~mm} \text { de diámetro (púrpura) } \\
\text { - Tiempo de relleno capilar } \geq 3 \text { segundos } \\
\text { - Rigidez de nuca }\end{array}$ \\
\hline Meningitis $^{1}$ & $\begin{array}{l}\text { Rigidez de nuca } \\
\text { Fontanela tensa } \\
\text { Depresión del nivel de conciencia } \\
\text { Status epiléptico }\end{array}$ \\
\hline Encefalitis herpética & $\begin{array}{l}\text { Signos neurológicos focales } \\
\text { Convulsiones focales } \\
\text { Disminución del nivel de conciencia }\end{array}$ \\
\hline Neumonía & $\begin{array}{l}\text { Taquipnea, definida por: } \\
\text {-FR }>60 / \text { min. en niños de } 0 \text { a } 5 \text { meses } \\
\text {-FR }>50 / \text { min. en niños de } 6 \text { a } 12 \text { meses } \\
\text {-FR }>40 / \text { min. en niños }>12 \text { meses } \\
\text { Crepitantes } \\
\text { Aleteo nasal } \\
\text { Tiraje } \\
\text { Cianosis } \\
\text { Saturación de oxígeno } \leq 95 \%\end{array}$ \\
\hline $\begin{array}{l}\text { Infección del tracto urinario (en } \\
\text { niños >3 meses de edad) }{ }^{2}\end{array}$ & $\begin{array}{l}\text { Vómitos } \\
\text { Hiporexia } \\
\text { Letargo } \\
\text { Irritabilidad } \\
\text { Dolor o hipersensibilidad abdominal } \\
\text { Polaquiuria o disuria } \\
\text { Orina maloliente o hematuria }\end{array}$ \\
\hline Artritis séptica u Osteomielitis & $\begin{array}{l}\text { Edema de un miembro o articulación } \\
\text { Impotencia funcional } \\
\text { Rechazo de la deambulación }\end{array}$ \\
\hline Enfermedad de Kawasaki ${ }^{3}$ & $\begin{array}{l}\text { Fiebre de duración }>5 \text { días y al menos uno de los siguientes: } \\
\text {-Inyección conjuntival bilateral } \\
\text {-Cambios en las membranas mucosas del tracto respiratorio superior (por ejemplo faringe congestiva, labios secos partidos o lengua } \\
\text { aframbuesada) } \\
\text {-Cambio en las extremidades periféricas (por ejemplo edema, eritema o descamación) } \\
\text {-Rash polimorfo } \\
\text {-Linfadenopatía cervical }\end{array}$ \\
\hline
\end{tabular}

FR: Frecuencia respiratoria.

'Los signos clásicos (rigidez de nuca, fontanela tensa, llanto agudo) a menudo están ausentes en lactantes con meningitis bacteriana. ${ }^{2}$ La infección del tracto urinario debería considerase en cualquier niño $<3$ meses de edad con fiebre.

${ }^{3}$ Nota: en algunos casos, enfermedad de Kawasaki incompleta/atípica puede ser diagnosticada con menos signos.

\section{Escenarios de atención del niño con fiebre}

\section{Manejo por evaluación remota}

Este escenario implica que el profesional de la salud no puede o no sabe como examinar al niño (por ejemplo ante una consulta o triage telefónico). Los niños con signos "rojos" pero que no se consideren en riesgo inmediato de vida deberían ser urgentemente evaluados clínicamente (anamnesis y examen físico) por un profesional de salud dentro de las dos horas. Aquellos con signos "amarillos" deben ser enviados a una evaluación clínica, empleando el juicio clínico para determinar la urgencia de esta evaluación. Los niños con signos "verdes" pueden ser manejados en el hogar, siempre y cuando se brinde a los padres el consejo apropiado, que incluya pautas de alarma de reconsulta (tabla 3).

Manejo por el médico no-pediatra

Si está presente alguno de los signos rojos, el niño debe ser derivado en forma urgente para su evaluación por un pediatra. Si está presente alguno de los signos "amarillos" y no se ha establecido un diagnóstico, los profesionales de la salud deberán optar por establecer con los padres o cuidadores una red de cuidados (ver tabla 4) o, en su defecto, derivar al niño para que sea evaluado por un pediatra. Como en el escenario anterior, ante los casos de niños con signos "verdes" estos pueden ser manejados en el hogar, siempre y cuando se brinde a los padres el consejo apropiado, que incluya pautas de alarma de reconsulta (tabla 3 ). 
Se desaconseja la prescripción de antibióticos orales a niños con fiebre sin foco aparente. Sin embargo, si se sospecha enfermedad meningocócica (ver tabla 2), se recomienda administrar antibióticos parenterales tempranamente (ya sea bencil-penicilina o una cefalosporina de tercera generación).

\section{Manejo por el especialista en pediatría}

Niños menores de 3 meses (no tiene en cuenta el sistema de luces de semáforo): Se deberá observar y monitorear la temperatura, frecuencia cardiaca y frecuencia respiratoria. Además, se deberá complementar la evaluación mediante hemograma completo, hemocultivo, proteína $C$ reactiva, análisis de orina para investigar infección urinaria, radiografía de tórax (si presenta signos respiratorios) y/o coprocultivo (si presenta diarrea). Se deberá realizar punción lumbar e iniciar antibióticos parenterales en niños menores de un mes, en niños de uno a tres meses que lucen enfermos o que presenten recuento de leucocitos $<5.000$ o $>15.000 / \mathrm{ml}$. Siempre que sea posible se debe realizar la punción lumbar antes de la administración de antibióticos.

Niños mayores de 3 meses: En niños con signos "verdes" se deberá realizar análisis de orina para investigar la presencia de infección urinaria. No se recomienda realizar laboratorio de sangre o radiografías de tórax de rutina.

En niños con signos "amarillos", si no se alcanzó el diagnósti$\mathrm{co}$, se recomienda realizar (a menos que se considere innecesario) análisis de orina, hemograma completo, hemocultivo y proteína $\mathrm{C}$ reactiva. Se recomienda completar la evaluación con radiografía de tórax si existe fiebre $>39^{\circ} \mathrm{C}$ y recuento de leucocitos $>20.000 / \mathrm{ml}$. Se considerara la punción lumbar si el niño es menor al año de edad.

En niños con signos "rojos", si no se alcanzó el diagnóstico, se recomienda realizar análisis de orina, hemograma completo, hemocultivo, y proteína $\mathrm{C}$ reactiva. Los siguientes estudios también deben ser considerados según lo sugiera el cuadro clínico: -punción lumbar en niños de todas las edades (si no esta contraindicado); -radiografía de tórax (sin tener en cuenta la temperatura corporal y el recuento de leucocitos); -electrolitos séricos y gases en sangre.

Cuando luego de realizar estas evaluaciones aún no se logra el diagnóstico, se debe manejar a los niños con signos "verdes" en el hogar, siempre y cuando se brinde a los padres el consejo apropiado, que incluya pautas de alarma de reconsulta (tabla 3). En cambio en los casos amarillos o rojos se debe considerar la admisión al hospital, teniendo en cuenta las circunstancias clínicas y sociales. En los casos en los que no se ha podido establecer un diagnóstico, pero que no se requiera internación se deberá establecer con los padres o cuidadores una red de cuidados (ver tabla 4)

En cuanto a los niños que requieran iniciar tratamiento inmediato se recomienda seguir las siguientes pautas:

- Administrar fluidos intravenosos de manera inmediata ante signos de shock: cloruro de sodio al $0,9 \%$ en bolos de $20 \mathrm{ml} / \mathrm{kg}$, pudiendo repetirse según sea necesario.

- Administrar oxígeno si existen signos de shock, la saturación de oxígeno es $<92 \%$ o este clínicamente indicado.

- Administrar aciclovir endovenoso si se sospecha encefalitis por herpes simplex.

- Administrar antibióticos parenterales a los niños febriles con signos de shock, deterioro del sensorio, signos de enfermedad meningocóccica, edad menor al mes, uno a tres meses con leucocitos $<5.000$ o $>15.000 / \mathrm{ml}$, o uno a tres meses que lucen enfermos. Si está indicado el tratamiento antibiótico inmediato, debe ser activo contra Neisseria meningitidis, Streptococcus pneumoniae, Escherichia coli, Stahylococcus aureus y Haemophilus influenzae tipo b (por ejemplo cefalosporinas de tercera generación, por ej. cefotaxima o ceftriaxona). Se recomienda agregar un antibiótico activo contra Listeria si el niño es menor a tres meses (por ej. amoxicilina o ampicilina). $\mathrm{Si}$ las tasas de resistencia bacteriana son significativas, emplear guías locales de prescripción.

Tabla 3: Recomendaciones generales de manejo de los niños con fiebre.

\section{Aconsejar a los padres y cuidadores sobre:}

Las recomendaciones de uso de antitérmicos (ver tabla 5).

Ofrecer al niño líquidos regularmente (continuar normalmente la lactancia).

Buscar signos de deshidratación: fontanela hundida, boca seca, ojos hundidos, llanto

sin lágrimas, mal estado general.

Estimular al niño a beber más líquidos y considerar buscar mayor consejo si observan signos de deshidratación.

Cómo identificar un rash que no desaparece a la vitropresión.

Observar al niño durante la noche.

Mantener al niño en el hogar mientras la fiebre persista y notificar al jardín o escuela sobre la enfermedad.

\section{Pautas de alarma para concurrir nuevamente a la consulta}

Si el niño presenta una convulsión.

Si el niños desarrolla un rash que no desaparece a la vitropresión.

Si perciben que la salud del niño está empeorando.

Si se sienten más preocupados que cuando recibieron consejo por última vez.

Si la fiebre dura más de cinco días

Si consideran que son incapaces de cuidar a su niño.

Tabla 4: Recomendaciones para establecer una red de cuidados.

Proveer al padre o cuidador información verbal o escrita sobre síntomas de alarma y cómo acceder a niveles mas apropiados de cuidados.

Establecer una visita de seguimiento en un tiempo y lugar específicos. Establecer contacto con otros profesionales de la salud, para asegurar el acceso y el seguimiento directo del niño en caso de requerirse una evaluación de mayor complejidad.

Tabla 5: Recomendaciones sobre el uso de antitérmicos

No se recomiendan los baños de esponja con agua tibia.

No abrigar en exceso ni desabrigar al niño con fiebre.

Considerar el uso indistinto de paracetamol o ibuprofeno si el niño parece incómodo 0 con dolor.

Tomar en cuenta las opiniones y deseos de padres y cuidadores cuando se considere el uso de agentes antipiréticos.

No administrar rutinariamente drogas antipiréticas a un niño con fiebre con el único objetivo de disminuir la temperatura corporal.

No administrar paracetamol e ibuprofeno al mismo tiempo, pero considerar el uso del agente alternativo cuando el niño no responde a la primera droga.

Los agentes antipiréticos no previenen las convulsiones febriles y no deberían ser utilizados específicamente para este propósito.

No prescribir antibióticos orales a un niño con fiebre sin foco aparente. 


\section{Comentario}

La enfermedad febril en los niños es un motivo de consulta muy frecuente en la práctica clínica y su manejo por los profesionales de la salud es a menudo muy variable. Esta guía de práctica clínica tiene en cuenta todos los ámbitos de atención de niños con enfermedad aguda, incluyendo atención primaria y secundaria.

La misma fue desarrollada en 2007 por un grupo dependiente del Instituto Nacional para la Salud y la Excelencia Clínica (NICE), basando sus recomendaciones en revisiones sistemáticas de la mejor evidencia disponible en respuesta a preguntas clínicas. En las áreas donde se identificaban preguntas clínicas importantes con mínima evidencia se emplearon técnicas de consenso formal. Está prevista su actualización en un lapso de tiempo no mayor a seis años. La mayoría de las recomendaciones son específicas, y aunque en algunas de ellas se apela al juicio clínico del operador, las distintas opciones para el manejo de la enfermedad se presentan claramente a través de diagramas de flujo, tablas y cuadros sinópticos.

El grupo de desarrollo de la presente guía fue financiado a través del sistema de salud nacional de Inglaterra (NHS) acorde a la estructura local del mismo, razón por la cual es posible que su aplicabilidad se vea limitada en otros países diferentes al Reino Unido. Sin embargo creemos que el core de sus recomendaciones pueden ser tenidas en cuenta y aplicadas en gran parte también en nuestro medio. Si bien esta guía ha sido publicada hace ya algunos años, creemos pertinente su divulgación dado que trata un tema clínico sumamente relevante y frecuente.

\section{Conclusiones del comentador}

Luego de aplicar el instrumento AGREE ${ }^{1}$ para la evaluación de calidad de guías de práctica clínica, se puede concluir que la guía resumida en este artículo resulta recomendada con condiciones o modificaciones que surgen fundamentalmente de los aspectos relacionados a su aplicabilidad e independencia editorial.

Valeria Vietto y Gabriel Villalón [ Servicio de Medicina Familiar y Comunitaria del Hospital Italiano de Buenos Aires valeria.vietto@hospitalitaliano.org.ar ]

Recibido el 02/02/2010 y aceptado el 05/05/2010

Vietto V. y Villalón G. Evaluación y manejo inicial de la enfermedad febril en el niño menor de cinco años. Evid Act Pract Ambul. 13(3). 102-105. JulSept 2010. Comentado de: National Institute for Health and Clinical Excellence. Quick reference guide: Feverish illness: assessment and initial management in children younger than 5 years (online). London: NICE, 2007. Disponible en: http://www.nice.org.uk/CG047 (último acceso 05/09/2010).

\section{Referencias}

1. The AGREE Collaboration. Appraisal of Guidelines for Research \& Evaluation (AGREE) Instrument (online).

Disponible en: www.agreecollaboration.org (ultimo acceso 05/09/2010)

Nota: las guías NICE son desarrolladas para su aplicación dentro del Servicio Nacional de Salud (sigla en inglés NHS) en el Reino Unido. El NICE no toma responsabilidad alguna por la traducción al español aquí publicada de la presente guía. 